\title{
The Association Between Three Genetic Variants in MicroRNAs (Rs11614913, Rs2910164, Rs3746444) and Prostate Cancer Risk
}

\author{
Yuanyuan Mib Kewei Renc Jiangang Zou ${ }^{a} \quad$ Yu Bai $^{\mathrm{a}} \quad$ Lifeng Zhang $^{\mathrm{a}} \quad$ Li Zuo $^{\mathrm{a}}$ \\ Atsushi Okadad $^{d}$ Takahiro Yasuid $^{d}$ \\ aDepartment of Urology, The Affiliated Changzhou No. 2 People's Hospital of Nanjing Medical \\ University, 29 Xinglong Road, Changzhou, bepartment of Urology, Third Affiliated Hospital of Nantong \\ University, 585 Xingyuan Road, Wuxi, 'Department of Orthopedics, the Affiliated Jiangyin Hospital of \\ Southeast University Medical School, Jiangyin, China dDepartment of Nephrourology, Nagoya City \\ University Graduate School of Medical Sciences, Aichi, Japan
}

\section{Key Words}

Microrna • Polymorphism • Prostate cancer • Meta-analysis

\begin{abstract}
Background/Aims: MicroRNAs (miRNAs) are a class of small non-coding RNA molecules which play a significant role in transcriptional and translational regulation. Published data on the association between the miRNA SNPs and prostate cancer $(\mathrm{PCa})$ risk are somewhat inconclusive. Methods: We performed a meta-analysis of all available studies including 2,227 patients and 2,331 control subjects to evaluate the impact of three common genetic variants of microRNAs in prostate cancer risk. Odds ratios (ORs) with 95\% confidence intervals (CIs) were utilized to investigate the strength of the association. Results: For miR-499 polymorphism, a significant association was observed between the rs3746444 A>G polymorphism and PCa risk in heterozygote comparison and dominant genetic model, in particular in Asian population subgroup. For miR-146a polymorphism, the rs2910164 CC genotype was associated with decreased PCa risk in Asian population in homozygote comparison. In addition, rs2910164 CC genotype had a weekly higher percentage value in subgroup of Gleason score $<7$. Similar results were also indicated in localized prostate cancer in subgroup analysis by tumor stage. For miR-196a2 polymorphism, no association was observed between this variant and PCa risk in the overall group. However, in stratified analysis by ethnicity, we found that rs11614913 T allele was a risk factor for Asian PCa patients. Conclusions: Polymorphisms of miR-196a2 rs11614913, miR-146a rs2910164, and miR-499 rs3746444 may contribute to the risk for developing prostate cancer in Asian descendants. Moreover, miR-146a rs2910164 polymorphism was related to PCa prognosis.

Yuanyuan Mi, Kewei Ren and Jiangang Zou contributed equally to this work.

Yu Bai

and Lifeng Zhang




\section{Introduction}

Prostate cancer (PCa) is one of the most common malignant tumor among men in the United States [1] However, the exact etiology underlying the development and progression of PCa is still poorly understood. Published researches indicated that both environmental and genetic factors may contribute to the development and progression of PCa [2, 3]. Single nucleotide polymorphism (SNP) is thought to be the most common type of genetic variation and has been indicated to be associated with the PCa risk $[4,5]$. Genome wide association studies (GWAS) have indicated that more than 100 SNPs associated with predisposition to PCa. However, the molecular mechanisms of these SNPs remain poorly defined [6].

MicroRNAs (MiRNAs) are a family of small single-stranded short (17-25 nucleotides) RNAs, which are evolutionarily well conserved but are non-proteincoding [7-9]. These RNAs are predicted to regulate gene expression at the posttranscriptional level through binding to $3^{\prime}$-untranslated region (3'-UTR) of the target mRNAs and consequently lead to mRNA cleavage or translational repression $[10,11]$. Published studies have indicated that miRNAs regulate the expression of roughly $10-30 \%$ of the all human genes [12], contributing to excessive physiologic and pathologic process, including apoptosis, proliferation, and immune response, which are known to play critical roles in carcinogenesis [13-15].

To date, many epidemiological studies have demonstrated the relationship between SNPs in miRNAs and cancer susceptibility, including gastric cancer $[16,17]$, breast cancer $[18,19]$, bladder cancer $[20,21]$ and other cancers [22-24]. Present studies indicated that miR-146a rs2910164 polymorphism marginally decreased the gastric cancer risk [25] and the miR-499 $A>G$ (rs3746444) polymorphism might be related to susceptibility to cancer [26]. However, there is inconsistent and little data regarding the impact of miRNA gene polymorphisms on prostate cancer susceptibility. Some researchers found that rs2910164 minor allele C confers reduced risk of PCa in Chinese Han population [27], whereas another researches revealed no evidence of association between this variant and PCa risk, nor with the relevant parameters of cancer prognosis in North Indian population [28]. Therefore, a meta-analysis of all eligible published case-control studies [27-32] was conducted to evaluate the effect of three MiRNA SNPs (miR-146a rs2910164, miR-196a2 rs11614913, miR-499 rs3746444) on PCa risk. Additionally, interaction between miR-146a rs2910164 polymorphism and several PCa prognostic parameters were also evaluated.

\section{Materials and Methods}

Search strategy and identification of eligible studies

PubMed database searches were carried out utilizing the following keywords: 'microRNA 146a/196a2/499' or 'mir-146a/196a2/499', 'prostate cancer' and 'polymorphism' (last search updated on May 01, 2017). Review articles and bibliographies of other relevant studies were also screened by a hand search. All the studies would be included if they met the following criteria: (a) full-text study; (b) utilizing an unrelated case-control design; (c) study published in English; (d) sufficient data for estimating an odds ratio (OR) with 95\% confidence interval (CI); (e) availability of genotypes or allele frequencies.

\section{Data extraction and quality assessment}

Data were collected on the genotype of mir-146a/196a2/499 according to prostate cancer. For each publication, all data complying with the selection criteria were reviewed and extracted independently by two of the investigators. In the case of a conflict, an agreement should be reached by the discussion between two reviewers. If they could not reach a consensus, discrepancies would be adjudicated by a third reviewer until the consensus was achieved on every item. For each study, the following characteristics were extracted: first author's last name, year of publications, country of origin, ethnicity, study-design (sources of controls), sample size in cases and controls, the number of cases and controls with variant allele and wild type, and genotyping methods respectively. 


\section{Cellular Physiology Cell Physiol Biochem 2018;48:149-157 and Biochemistry Published online: July 12, $2018 \quad \begin{aligned} & \text { DOI: 10.1159/000491671 } 2018 \text { The Author(s). Published by S. Karger AG, Basel } \\ & \text { www.karger.com/cpb }\end{aligned}$ \\ Mi et al.: MicroRNA Polymorphism and PCa Risk}

\section{Statistical analysis}

The strength of association between the three microRNA SNPs and prostate cancer risk was measured by odds ratios (ORs) with 95\% confidence intervals (CIs). To evaluate the wild-type homozygote (WW), the risk of the rare allele homozygote (RR) and heterozygous (WR) genotypes on prostate cancers were assessed. Moreover, we tested the prostate cancer susceptibility under a dominant model (RR+WR vs. WW) and recessive model (RR vs. WR+WW). Furthermore, subgroup analysis was stratified by ethnicity (Asian and Caucasian), source of control (population-based and hospital-based), Gleason score and tumor stage. Heterogeneity across the studies was assessed by utilizing the Chi-square-based Q-statistic test and it was considered significant when $P$ value of heterogeneity less than 0.05 . The data were combined utilizing both random effects (the DerSimonian and Laird method) models and fixed-effects (the Mantel-Haenszel method). When the heterogeneity existed, a random-effect model was conducted [33, 34]; otherwise, the fixed-effect model was performed to pool the results [35]. We used $Z$-test to calculate the statistical significance of the pooled $O R$ and a $P$ value of $<0.05$ was considered significant. Moreover, a sensitivity analysis was applied to evaluate the stability of the results. Funnel plots and Egger's linear regression tests were performed to determine whether the publication bias was exist [36]. All the statistical tests for this meta-analysis were conducted with STATA version 11.0 (Stata Corporation College Station, TX, USA).

\section{Results}

\section{Study characteristics}

A total of six eligible papers according to the inclusion criteria were enrolled in this study (Fig. 1). Study characteristics of the eligible studies are pooled in Table 1. We checked the three microRNAs' Minor Allele Frequency (MAF) reported for the main worldwide populations. For rs11614913: American (AMR), 0.389; African (AFR), 0.140; East Asian (EAS), 0.458; South Asian (SAS), 0.258; and European (EUR), 0.410. For rs3746444: AMR, 0.134; AFR, 0.169; EAS, 0.145; SAS, 0.267; and EUR, 0.194. For rs2910164: EUR, 0.239; AFR, 0.391; and China (CHN), 0.354 (Fig. 2 a-c). For rs2910164 polymorphism, five studies with available data were enrolled in the pooled analysis. In the subgroup of ethnicity, four were performed in Asian descendants and one was in European descendants. Hospital based controls were carried out in four of the studies. Furthermore, four publications containing available genotype frequency information investigated PCa prognostic parameters. The association between rs2910164 polymorphism and PCa risk stratified by disease stage (localized: T1-2N0M0; advanced: T3-4NxMx or TxN1Mx or TxNxM1) and pathologic grade (Gleason score $<7$ and $\geqslant 7$ ) is shown in Table 3-4. For rs11614913 polymorphism, three studies with available data were enrolled. There were two studies of Asian descendent and one of Caucasian ethnicity. Hospital based controls were carried out in two of the studies. For rs3746444 polymorphism, three studies covered Serbia, India and Iran related to prostate

Table 1. Basic information for included studies of the association between three miRs' polymorphisms and PCA susceptibility. HB: hospital-based; PB: population-based; PCR-RFLP: polymerase chain reaction and restrictive fragment length polymorphism; HRMA: high resolution melting analysis; T-ARMS-PCR: tetra amplification refractory mutation system-polymerase chain reaction; qRT-PCR: real-time quantitative reverse transcription-PCR; MAF: Minor Allele Frequency

\begin{tabular}{lcccccccccccccc}
\hline Author & Year & Origin & Ethnicity & Design & Case & Control & Case & & & & Control & Genotype \\
methods
\end{tabular}


cancer were included. To analyze polymorphisms, genotyping by the classical genotyping method (polymerase chain reaction-restriction fragment length polymorphism, PCR-RFLP) were carried out by all of the studies, in which two were hospital-based and one was population-based.

\section{Quantitative synthesis}

For miR-146a polymorphism, no significant risk association was observed when all the eligible studies were pooled into the analysis: heterozygote comparison (fixed-effects OR $=0.87,95 \% \mathrm{CI}=0.68-1.12, P_{\text {heterogeneity }}$ $=0.639, P=0.292$ ), homozygote comparison (fixedeffects $\mathrm{OR}=0.71,95 \% \mathrm{CI}=0.49-1.05, P_{\text {heterogeneity }}=$ $0.222, P=0.084$ ) and the dominant genetic model (fixed-effects OR $=0.85,95 \% \mathrm{CI}=0.66-1.08, P_{\text {heterogeneity }}$ $=0.386 P=0.180$ ) (Table 2). However, in the subgroup

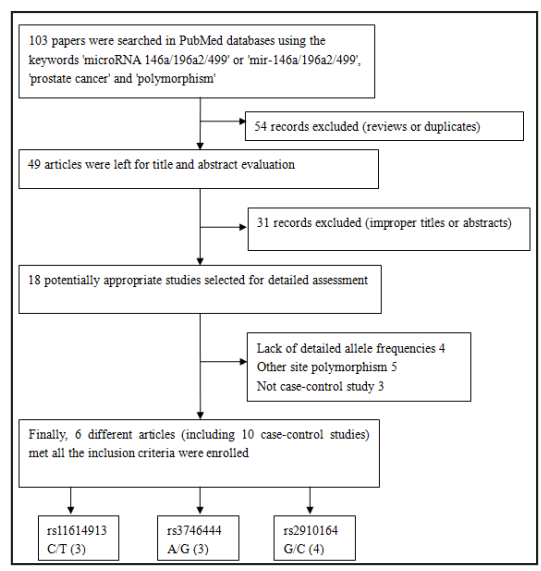

Fig. 1. Flow diagram of the strategy of literature search among the associated studies. analysis by ethnicity, obvious associations between rs2910164 G>C polymorphism and prostate cancer risk were observed in Asian descendants for homozygote comparison (fixed-effects $\mathrm{OR}=0.64,95 \% \mathrm{CI}=0.42-0.98, P_{\text {heterogeneity }}$ $=0.221, P=0.040$ ), but not in European descendants. Furthermore, the rs2910164 CC genotype had a weekly higher percentage value in subgroup of Gleason score < 7 (OR $=1.62,95 \% \mathrm{CI}=1.07-2.47, P_{\text {heterogeneity }}=0.220, P=0.023$ Table 5). Similar results were also identified in localized prostate cancer in subgroup analysis by tumor stage $(\mathrm{OR}=1.64,95 \%$ $\mathrm{CI}=1.00-2.68, P_{\text {heterogeneity }}=0.609, P=0.048$ Table 6 ). For miR499 polymorphism, a significant association was observed between the rs3746444 A>G polymorphism and PCa risk in heterozygote comparison (fixed-effects $\mathrm{OR}=1.60,95 \% \mathrm{CI}=$ $1.28-2.01, P_{\text {heterogeneity }}=0.090, P<0.001$ ) and dominant genetic model (fixed-effects $\mathrm{OR}=1.45,95 \% \mathrm{CI}=1.17-1.80, P_{\text {heterogeneity }}$ $=0.257, P=0.001$ ) (Table 2), in particular in Asian population subgroup (heterozygote comparison OR $=2.03,95 \% \mathrm{CI}=$ $1.47-2.79, P_{\text {heterogeneity }}=0.404, P<0.001$; dominant genetic model OR $=1.70,95 \% \mathrm{CI}=1.26-2.30, P_{\text {heterogeneity }}=0.450, P$ $=0.001$ ). For miR-196a 2 polymorphism, no association was observed between rs11614913 C>T variant and PCa risk in the overall group: heterozygote comparison (fixed-effects OR $\left.=1.14,95 \% \mathrm{CI}=0.91-1.42, P_{\text {heterogeneity }}=0.054, P=0.262\right)$, homozygote comparison (fixed-effects OR $=0.93,95 \% \mathrm{CI}=$ $\left.0.62-1.38, P_{\text {heterogeneity }}=0.215, P=0.704\right)$ and the dominant genetic model (fixed-effects $\mathrm{OR}=1.11,95 \% \mathrm{CI}=0.90-1.38$, $P_{\text {heterogeneity }}=0.056 P=0.335$ ) (Table 2). However, in stratified analysis by ethnicity, we found that rs11614913 T allele was a risk factor for Asian PCa patients (heterozygote comparison $\mathrm{OR}=1.41,95 \% \mathrm{CI}=1.04-1.91, P_{\text {heterogeneity }}=0.193, P=0.027$; dominant genetic model $\mathrm{OR}=1.40,95 \% \mathrm{CI}=1.04-1.89$, $P_{\text {heterogeneity }}=0.333, P=0.027$ ), but not in European descendants (heterozygote comparison $\mathrm{OR}=0.88,95 \% \mathrm{CI}=0.64-1.23, P$ $=0.459$; dominant genetic model $\mathrm{OR}=0.86,95 \% \mathrm{CI}=0.63-$ $1.18, P=0.351$ ).

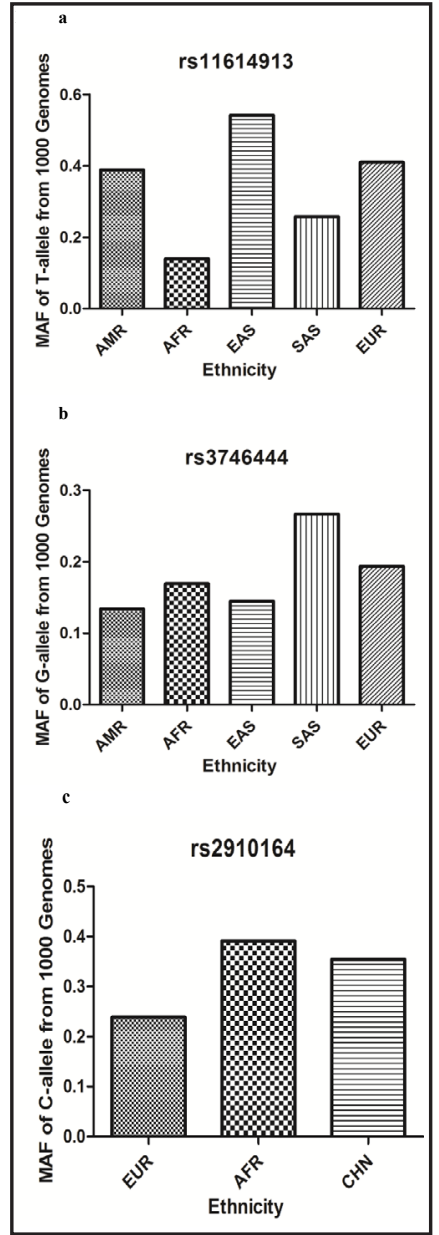

Fig. 2. Minor allele frequencies for three miRs' polymorphisms in the controls stratified by ethnicity. Vertical line, minor allele frequency; Horizontal line, ethnicity type. 
Table 2. Total and stratified subgroup analysis for three miRs' polymorphisms and PCA susceptibility

\begin{tabular}{|c|c|c|c|c|c|}
\hline Variables & $\mathrm{N}$ & Case / & OR(95\%CI) $\quad P_{h} \quad P$ & OR(95\%CI) $\quad \mathrm{P}_{\mathrm{h}} \quad \mathrm{P}$ & OR(95\%CI) $\quad P_{h} \quad P$ \\
\hline \multicolumn{6}{|c|}{ Control } \\
\hline \multicolumn{3}{|c|}{ miR-196a2 rs11614913 } & \multirow{2}{*}{$\begin{array}{c}\text { TC vs. CC } \\
1.14(0.91-1.42) 0.054 \\
0.262\end{array}$} & \multirow{2}{*}{$\begin{array}{c}\text { TT vs. CC } \\
0.93(0.62-1.38) 0.215 \\
0.704\end{array}$} & \multirow{2}{*}{$\begin{array}{c}\text { TT+TC vs. CC } \\
1.11(0.90-1.38) 0.056 \\
0.335\end{array}$} \\
\hline Total & 3 & $679 / 721$ & & & \\
\hline \multicolumn{6}{|l|}{ Ethnicity } \\
\hline Asian & 2 & $328 / 412$ & $1.41(1.04-1.91) 0.1930 .027$ & $\begin{array}{c}1.24(0.64-2.42) 0.173 \\
0.526\end{array}$ & \multirow{3}{*}{$\begin{array}{c}0.86(0.63-1.18)-0.351 \\
1.40(1.04-1.89) 0.333 \\
0.027 \\
\text { GG+GA vs. AA } \\
1.45(1.17-1.80) 0.257 \\
0.001\end{array}$} \\
\hline \multicolumn{3}{|c|}{ miR-499 rs3746444 } & \multirow{2}{*}{$\begin{array}{c}\text { GA vs. AA } \\
1.60(1.28-2.01) 0.090 \\
<0.001\end{array}$} & \multirow{2}{*}{$\begin{array}{c}\text { GG vs. AA } \\
0.96(0.65-1.42) 0.888 \\
0.844\end{array}$} & \\
\hline Total & 3 & $683 / 719$ & & & \\
\hline $\begin{array}{l}\text { Ethnicity } \\
\text { Caucasian }\end{array}$ & 1 & $355 / 307$ & $1.27(0.92-1.74)-0.149$ & $1.00(0.50-2.01)-0.993$ & \multirow{4}{*}{$\begin{array}{c}1.23(0.90-1.68)-0.187 \\
1.70(1.26-2.30) 0.450 \\
0.001 \\
\text { CC+CG vs. GG } \\
0.85(0.66-1.08) 0.386 \\
0.180\end{array}$} \\
\hline Asian & 2 & $328 / 412$ & $\begin{array}{c}2.03(1.47-2.79) 0.404 \\
<0.001\end{array}$ & $\begin{array}{c}0.94(0.59-1.51) 0.641 \\
0.808\end{array}$ & \\
\hline \multicolumn{3}{|c|}{ miR-146a rs2910164 } & CG vs. GG & \multirow{2}{*}{$\begin{array}{c}\text { CC vs. GG } \\
0.71(0.49-1.05) 0.222 \\
0.084\end{array}$} & \\
\hline Total & 4 & $865 / 891$ & $0.87(0.68-1.12) 0.6390 .292$ & & \\
\hline $\begin{array}{l}\text { Ethnicity } \\
\text { Caucasian }\end{array}$ & 1 & 286/199 & $1.00(0.68-1.48)-0.994$ & $1.20(0.46-3.14)-0.707$ & \multirow{2}{*}{$\begin{array}{c}1.02(0.70-1.49)-0.912 \\
0.74(0.53-1.02) 0.506 \\
0.063 \\
\end{array}$} \\
\hline Asian & 3 & $579 / 692$ & $0.79(0.56-1.10) 0.6500 .164$ & $\begin{array}{c}0.64(0.42-0.98) 0.221 \\
0.040\end{array}$ & \\
\hline
\end{tabular}

Table 3. Basic information for the association between miR-146a rs2910164 polymorphism in PCA by Gleason score

\begin{tabular}{lcccccc}
\hline Author & Origin & Ethnicity & Gleason score $<7$ & & Gleason score $>7$ & \\
\hline & & & CC & CG+GG & CC & CG+GG \\
Nikolic [32] & 2015 & Serbia & 11 & 149 & 1 & 112 \\
George [28] & 2011 & India & 24 & 25 & 52 & 58 \\
Hashemi [30] & 2016 & Iran & 7 & 50 & 6 & 106 \\
Xu [27] & 2010 & China & 16 & 50 & 32 & 153 \\
\hline
\end{tabular}

Table 4. Basic information for the association between miR-146a rs2910164 polymorphism in PCA by tumor stage

\begin{tabular}{lcccccc}
\hline Author & Origin & Ethnicity & Localized & \multicolumn{3}{c}{ Advanced } \\
\hline & & & CC & CG+GG & CC & CG+GG \\
Nikolic [32] & 2015 & Serbia & 7 & 96 & 4 & 156 \\
Xu [27] & 2010 & China & 31 & 105 & 17 & 98 \\
Hashemi [30] & 2016 & Iran & 9 & 113 & 4 & 43 \\
Chen [29] & 2014 & China & 15 & 41 & 3 & 13 \\
\hline
\end{tabular}

Table 5. Relationship between miR-146a rs2910164 polymorphism and PCA prognosis by Gleason score subgroup

\begin{tabular}{ccccccccc}
\hline miR-146a & Genotype & $\begin{array}{c}\text { Gleason } \\
<7\end{array}$ & $\begin{array}{c}\text { Gleason } \\
\geqslant 7\end{array}$ & OR $(95 \% \mathrm{CI})$ & $\mathrm{Ph}$ & $\mathrm{P}$ & Egger's test & Begg's test \\
\hline rs2910164 & $\mathrm{CC}$ & 58 & 91 & & & & & \\
& $\mathrm{CG}+\mathrm{GG}$ & 274 & 429 & $\begin{array}{c}1.62(1.07- \\
2.47)\end{array}$ & 0.220 & 0.023 & $\mathrm{t}=3.86, \mathrm{p}=0.061$ & $\mathrm{z}=1.70, \mathrm{p}=0.089$ \\
\hline
\end{tabular}

Table 6. Relationship between miR-146a rs2910164 polymorphism and PCA prognosis by tumor stage subgroup

\begin{tabular}{ccccccccc}
\hline miR-146a & Genotype & Localized & Advanced & OR(95\%CI) & $\mathrm{Ph}_{\mathrm{h}}$ & $\mathrm{P}$ & Egger's test & Begg's test \\
\hline rs2910164 & $\mathrm{CC}$ & 62 & 28 & & & & & \\
& $\mathrm{CG}+\mathrm{GG}$ & 355 & 310 & $\begin{array}{c}1.64(1.00- \\
2.68)\end{array}$ & 0.609 & 0.048 & $\mathrm{t}=1.43, \mathrm{p}=0.290$ & $\mathrm{z}=0.34, \mathrm{p}=0.734$ \\
\hline
\end{tabular}




\section{Publication bias}

The Egger's test and Begg's funnel plot were conducted to assess the publication bias of literatures. No obvious evidence of publication bias was found in miR-196a2 rs11614913 (TC vs. CC, $\mathrm{t}=1.17, P=$ 0.450 ; TT vs. $\mathrm{CC}, \mathrm{t}=1.04, P=0.296$ ; TT+TC vs. $\mathrm{CC}, \mathrm{t}=1.36, P=0.404$ ), miR-499 rs3746444 (GA vs. AA, $\mathrm{t}=$ 1.32, $P=0.412$; GG vs. $\mathrm{AA}, \mathrm{t}=1.56$, $P=0.363 ; \mathrm{GG}+\mathrm{GA}$ vs. $\mathrm{AA}, \mathrm{t}=2.30, P$ $=0.055)$, and miR-146a rs2910164 (CG vs. $\mathrm{GG}, \mathrm{t}=4.55, P=0.138$; $\mathrm{CC}$ vs. $\mathrm{GG}, \mathrm{t}=2.44, P=0.248 ; \mathrm{CC}+\mathrm{CG}$ vs. GG, $\mathrm{t}=5.12, P=0.123)$. The shape of the funnel plots seemed asymmetrical in heterozygote comparison for three miRs' polymorphisms, suggesting no publication bias (Fig. 3a-c).

\section{Discussion}

Genetic susceptibility to malignant tumors has led to accumulating attention to the studies of polymorphism genes involved in process of carcinogenesis. Previous researches have shown evidence that miRNAs are involved in various crucial biological processes through imperfect pairing with target mRNAs of protein-coding genes [37, 38]. Meta-analysis is used to combine the results based on individual research to yield summary conclusions, especially when results from single case-control studies were incomprehensive and conflicting. Several meta-analyses have been performed on the miRNA SNPs associated with the risk of overall cancer [39-41]. However, none of the meta-analyses has focused on prostate cancer independently for short of eligible data. In the present study, novel casecontrol studies from the last years were enrolled and some new findings have been indicated.

Our results demonstrated that polymorphisms of miR-196a2 rs11614913, miR-146a rs2910164, and miR-499 rs3746444 may contribute to the risk for developing prostate cancer in Asian descendants. Tumor stage and Gleason score could be considered as prognostic factors for prostate cancer, if the Tumor stage is higher than T2c or Gleason score is more than 7 , individuals must have a worse prognosis and this cancer will show more aggressive. The present study indicated that individuals who carried rs2910164 CC genotype had a high percentage in Gleason score less than 7 and localized PCa group, manifesting that

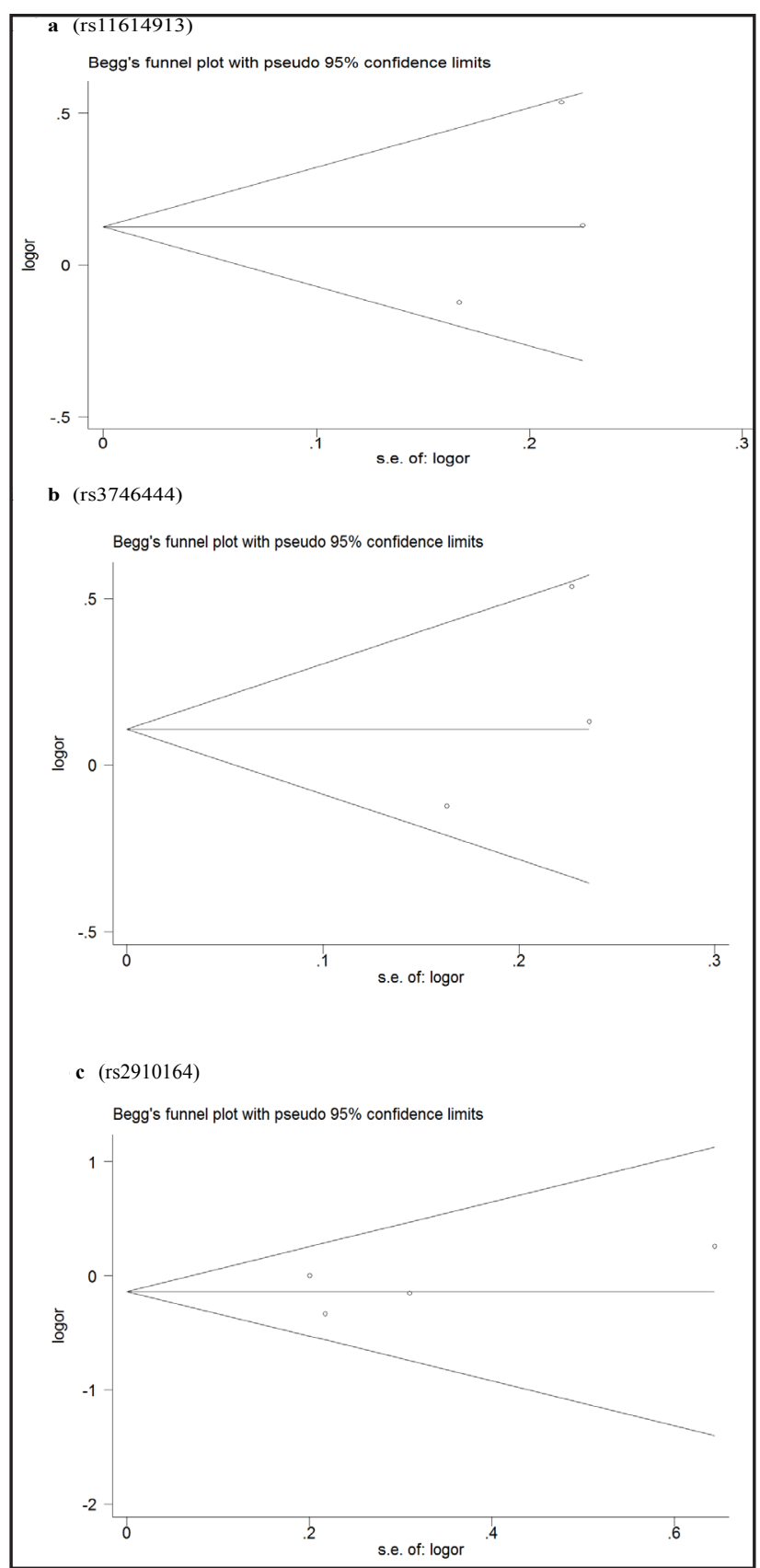

Fig. 3. Begg's funnel plot of standard error for assessing publication bias. 
rs2910164 G>C polymorphism was partly related to PCa prognosis. The rs11614913 C>T polymorphism present in the miR-196a2 has been indicated to be associated with various carcinogenesis [42-44]. Previous meta-analysis support that the rs11614913 TT genotype was associated with a decreased risk for breast cancer and lung cancer, although this variant was not associated with gastric cancer and hepatocellular carcinoma [42]. In the present study, we demonstrated that the rs11614913 TT genotype were associated with increased risk of prostate cancer in Asian descendants but not in Europeans. Published studies reported that rs3746444 G allele was an increased cancer risk factor in Chinese population, especially for breast cancer [45], our results indicated a significant association between the rs3746444 A $>$ G polymorphism and PCa risk, in particular in Asian population subgroup. Nevertheless, this meta-analysis still has some limitations. Firstly, although all eligible studies were enrolled, the relatively small sample size of studies could lead to reduced statistical power. For only one study was based on Caucasian descendants. Secondly, the detailed information such as age, environmental factors and life-style was not considered. Furthermore, the available data containing PCa prognostic parameters in miR-499 rs3746444 and miR-196a2 rs11614913 polymorphisms was not compatible. In addition, the present analysis did not assess any potential gene-environment interaction or gene-gene interaction due to lack of relevant published data.

Inconclusion, this meta-analysis evaluated theassociation of threemiRNA polymorphisms and prostate cancer risk. Our results showed evidence that miR-146a rs2910164 CC genotype was associated with decreased prostate cancer risk in Asian population. Moreover, this variant was probably related to PCa outcome. The miR-196a2 rs11614913 T allele was a risk factor for Asian PCa patients. Furthermore, the miR-499 polymorphism rs3746444 A $>$ G polymorphism was a risk factor for prostate cancer, especially in the Asian population. Further well-designed large studies are warranted to clarify the possible roles of these polymorphisms in more details.

\section{Acknowledgements}

This work was supported by grants from Changzhou Science and Technology International Cooperation Grant (No. : CZ20160017), Jiangsu '333 Project' Scientific Research Grant (No. : BRA 2016118), Changzhou High-Level Medical Talents Training Project (Number: 2016CZBJ035), Jiangsu Post-Doc Scientific Research Grant (No. :1701184C), Youth talent project of Wuxi Commission of Health and Family Planning (No. : QNRC043), Wuxi Commission of Health and Family Planning (No.: Q201746, Z201712, jzyx03), Science and Technology Bureau of Wuxi City (No. : CSE31N1605).

\section{Disclosure Statement}

The authors declare that they have no competing interests.

\section{References}

1 Siegel R, Ma J, Zou Z, Jemal A: Cancer statistics, 2014. CA Cancer J Clin 2014;64:9-29.

- Chokkalingam AP, Stanczyk FZ, Reichardt JK, Hsing AW: Molecular epidemiology of prostate cancer: hormone-related genetic loci. Front Biosci 2007;12:3436-3460.

3 Ntais C, Polycarpou A, Tsatsoulis A: Molecular epidemiology of prostate cancer: androgens and polymorphisms in androgen-related genes. Eur J Endocrinol 2003;149:469-477.

4 Chen H, Yu H, Wang J, Zhang Z, Gao Z, Chen Z, Lu Y, Liu W, Jiang D, Zheng SL, Wei GH, Issacs WB, Feng J, Xu J: Systematic enrichment analysis of potentially functional regions for 103 prostate cancer risk-associated loci. Prostate 2015;75:1264-1276. 


\section{Cellular Physiology Cell Physiol Biochem 2018;48:149-157

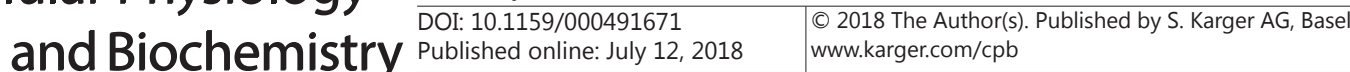

Mi et al.: MicroRNA Polymorphism and PCa Risk

-5 Huang Q Whitington T, Gao P, Lindberg JF, Yang Y, Sun J, Vaisanen MR, Szulkin R, Annala M, Yan J, Egevad LA, Zhang K, Lin R, Jolma A, Nykter M, Manninen A, Wiklund F, Vaarala MH, Visakorpi T, Xu J, Taipale J, Wei GH: A prostate cancer susceptibility allele at 6q22 increases RFX6 expression by modulating HOXB13 chromatin binding. Nat Genet 2014;46:126-135.

6 Spisak S, Lawrenson K, Fu Y, Csabai I, Cottman RT, Seo JH, Haiman C, Han Y, Lenci R, Li Q, Tisza V, Szallasi Z, Herbert ZT, Chabot M, Pomerantz M, Solymosi N, Gayther SA, Joung JK, Freedman ML: CAUSEL: an epigenome- and genome-editing pipeline for establishing function of noncoding GWAS variants. Nat Med 2015;21:1357-1363.

7 Ambros V: The functions of animal microRNAs. Nature 2004;431:350-355.

8 Bartel DP: MicroRNAs: genomics, biogenesis, mechanism, and function. Cell 2004;116:281-297.

-9 Ruan K, Fang X, Ouyang G: MicroRNAs: novel regulators in the hallmarks of human cancer. Cancer Lett 2009;285:116-126.

10 Cai Y, Yu X, Hu S, Yu J: A brief review on the mechanisms of miRNA regulation. Genomics Proteomics Bioinformatics 2009;7:147-154.

11 Fabian MR, Sonenberg N: The mechanics of miRNA-mediated gene silencing: a look under the hood of miRISC. Nat Struct Mol Biol 2012;19:586-593.

12 Berezikov E, Guryev V, van de Belt J, Wienholds E, Plasterk RH, Cuppen E: Phylogenetic shadowing and computational identification of human microRNA genes. Cell 2005;120:21-24.

13 Calin GA, Croce CM: MicroRNA signatures in human cancers. Nat Rev Cancer 2006;6:857-866.

14 Cho WC: MicroRNAs: potential biomarkers for cancer diagnosis, prognosis and targets for therapy. Int J Biochem Cell Biol 2010;42:1273-1281.

15 Garzon R, Croce CM: MicroRNAs and cancer: introduction. Semin Oncol 2011;38:721-723.

16 Hishida A, Matsuo K, Goto Y, Naito M, Wakai K, Tajima K, Hamajima N: Combined effect of miR-146a rs2910164 G/C polymorphism and Toll-like receptor $4+3725$ G/C polymorphism on the risk of severe gastric atrophy in Japanese. Dig Dis Sci 2011;56:1131-1137.

17 Zeng Y, Sun QM, Liu NN, Dong GH, Chen J, Yang L, Wang B: Correlation between pre-miR-146a C/G polymorphism and gastric cancer risk in Chinese population. World J Gastroenterol 2010;16:3578-3583.

18 Hu Z, Liang J, Wang Z, Tian T, Zhou X, Chen J, Miao R, Wang Y, Wang X, Shen H: Common genetic variants in pre-microRNAs were associated with increased risk of breast cancer in Chinese women. Hum Mutat 2009;30:79-84.

19 Pastrello C, Polesel J, Della Puppa L, Viel A, Maestro R: Association between hsa-mir-146a genotype and tumor age-of-onset in BRCA1/BRCA2-negative familial breast and ovarian cancer patients. Carcinogenesis 2010;31:2124-2126.

-20 Mittal RD, Gangwar R, George GP, Mittal T, Kapoor R: Investigative role of pre-microRNAs in bladder cancer patients: a case-control study in North India. DNA Cell Biol 2011;30:401-406.

21 Yang H, Dinney CP, Ye Y, Zhu Y, Grossman HB, Wu X: Evaluation of genetic variants in microRNA-related genes and risk of bladder cancer. Cancer Res 2008;68:2530-2537.

22 Guo H, Wang K, Xiong G, Hu H, Wang D, Xu X, Guan X, Yang K, Bai Y: A functional varient in microRNA-146a is associated with risk of esophageal squamous cell carcinoma in Chinese Han. Fam Cancer 2010;9:599603.

-23 Liu Z, Li G, Wei S, Niu J, El-Naggar AK, Sturgis EM, Wei Q: Genetic variants in selected pre-microRNA genes and the risk of squamous cell carcinoma of the head and neck. Cancer 2010;116:4753-4760.

-24 Yue C, Wang M, Ding B, Wang W, Fu S, Zhou D, Zhang Z, Han S: Polymorphism of the pre-miR-146a is associated with risk of cervical cancer in a Chinese population. Gynecol Oncol 2011;122:33-37.

25 Wei Y, Li L, Gao J: The association between two common polymorphisms (miR-146a rs2910164 and miR196a2 rs11614913) and susceptibility to gastric cancer: A meta-analysis. Cancer Biomark 2015;15:235248.

26 Xu Z, Zhang E, Duan W, Sun C, Bai S, Tan X: The association between miR-499 polymorphism and cancer susceptibility: a meta-analysis. Onco Targets Ther 2015;8:2179-2186.

27 Xu B, Feng NH, Li PC, Tao J, Wu D, Zhang ZD, Tong N, Wang JF, Song NH, Zhang W, Hua LX, Wu HF: A functional polymorphism in Pre-miR-146a gene is associated with prostate cancer risk and mature miR146a expression in vivo. Prostate 2010;70:467-472. 


\section{Cellular Physiology Cell Physiol Biochem 2018;48:149-157 \begin{tabular}{l|l} 
DOI: 10.1159/000491671 & Ond Biochemistry 2018 The Author(s). Published by S. Karger AG, Basel \\
wwww.karger.com/cpb
\end{tabular} \\ Mi et al.: MicroRNA Polymorphism and PCa Risk}

28 George GP, Gangwar R, Mandal RK, Sankhwar SN, Mittal RD: Genetic variation in microRNA genes and prostate cancer risk in North Indian population. Mol Biol Rep 2011;38:1609-1615.

-29 Chen M, Zhou ZY, Chen JG, Tong N, Chen SQ, Yang Y, Zhang XW, Jiang H, Liu N, Liu J, Sha GZ, Zhu WD, Hua LX, Wang ZJ, Xu B: Effect of miR-146a polymorphism on biochemical recurrence risk after radical prostatectomy in southern Chinese population. Genet Mol Res 2014;13:10615-10621.

-30 Hashemi M, Moradi N, Ziaee SA, Narouie B, Soltani MH, Rezaei M, Shahkar G, Taheri M: Association between single nucleotide polymorphism in miR-499, miR-196a2, miR-146a and miR-149 and prostate cancer risk in a sample of Iranian population. J Adv Res 2016;7:491-498.

31 Nikolic Z, Savic Pavicevic D, Vucic N, Cidilko S, Filipovic N, Cerovic S, Vukotic V, Romac S, Brajuskovic G: Assessment of association between genetic variants in microRNA genes hsa-miR-499, hsa-miR-196a2 and hsa-miR-27a and prostate cancer risk in Serbian population. Exp Mol Pathol 2015;99:145-150.

32 Nikolic ZZ, Savic Pavicevic D, Vukotic VD, Tomovic SM, Cerovic SJ, Filipovic N, Romac SP, Brajuskovic GN: Association between genetic variant in hsa-miR-146a gene and prostate cancer progression: evidence from Serbian population. Cancer Causes Control 2014;25:1571-1575.

33 DerSimonian R, Laird N: Meta-analysis in clinical trials. Control Clin Trials 1986;7:177-188.

-34 Kim WH, Min KT, Jeon YJ, Kwon CI, Ko KH, Park PW, Hong SP, Rim KS, Kwon SW, Hwang SG, Kim NK: Association study of microRNA polymorphisms with hepatocellular carcinoma in Korean population. Gene 2012;504:92-97.

-35 Duval S, Tweedie R: Trim and fill: A simple funnel-plot-based method of testing and adjusting for publication bias in meta-analysis. Biometrics 2000;56:455-463.

-36 Egger M, Davey Smith G, Schneider M, Minder C: Bias in meta-analysis detected by a simple, graphical test. BMJ 1997;315:629-634.

37 Bartel DP, Chen CZ: Micromanagers of gene expression: the potentially widespread influence of metazoan microRNAs. Nat Rev Genet 2004;5:396-400.

-38 Chu R, Mo G, Duan Z, Huang M, Chang J, Li X, Liu P: miRNAs affect the development of hepatocellular carcinoma via dysregulation of their biogenesis and expression. Cell Commun Signal 2014;12:45.

39 Qiu LX, He J, Wang MY, Zhang RX, Shi TY, Zhu ML, Mao C, Sun S, Lv FF, Zheng CL, Zhu XD: The association between common genetic variant of microRNA-146a and cancer susceptibility. Cytokine 2011;56:695-698.

40 Wang F, Ma YL, Zhang P, Yang JJ, Chen HQ, Liu ZH, Peng JY, Zhou YK, Qin HL: A genetic variant in microRNA196a2 is associated with increased cancer risk: a meta-analysis. Mol Biol Rep 2012;39:269-275.

41 Zhang J, Liu YF, Gan Y: Lack of association between miR-149 C>T polymorphism and cancer susceptibility: a meta-analysis based on 4, 677 cases and 4, 830 controls. Mol Biol Rep 2012;39:8749-8753.

42 He B, Pan Y, Cho WC, Xu Y, Gu L, Nie Z, Chen L, Song G, Gao T, Li R, Wang S: The association between four genetic variants in microRNAs (rs11614913, rs2910164, rs3746444, rs2292832) and cancer risk: evidence from published studies. PLoS One 2012;7:e49032.

43 Li XD, Li ZG, Song XX, Liu CF: A variant in microRNA-196a2 is associated with susceptibility to hepatocellular carcinoma in Chinese patients with cirrhosis. Pathology 2010;42:669-673.

-44 Zhan JF, Chen LH, Chen ZX, Yuan YW, Xie GZ, Sun AM, Liu Y: A functional variant in microRNA-196a2 is associated with susceptibility of colorectal cancer in a Chinese population. Arch Med Res 2011;42:144-148.

45 Xu Y, Gu L, Pan Y, Li R, Gao T, Song G, Nie Z, Chen L, Wang S, He B: Different effects of three polymorphisms in MicroRNAs on cancer risk in Asian population: evidence from published literatures. PLoS One 2013;8:e65123. 